\title{
FATIGUE PROPERTIES OF POLYURETHANE FOAMS, WITH SPECIAL EMPHASIS ON AUXETIC FOAMS, USED FOR HELICOPTER PILOT SEAT CUSHION INSERTS
}

\author{
Janusz Lisiecki \\ Dominik Nowakowski \\ Piotr Reymer
}

\begin{abstract}
Air Force Institute of Technology, ul. Księcia Bolesława 6, 01-494 Warsaw, Poland
janusz.lisiecki@itwl.pl,dominik.nowakowski@itwl.pl,piotr.reymer@itwl.pl
\end{abstract}

\begin{abstract}
Seat cushion inserts in military helicopters crew seats, as suggested by the helicopters manufacturers, are made of traditional polyurethane foams.

Elastic polyurethane auxetic foams are materials that exhibit different utility properties compared to traditionally used polyurethane foams, such as polyether or polystyrene foams. All the differences result from the primary physical property of elastic polyurethane auxetic foams which is a negative Poisson's ratio. Auxetic materials are characterized by better utility properties than conventional foam materials - they can potentially increase safety in the event of a crash and offer higher comfort during regular use. Application of auxetic materials as seat cushion inserts would also decrease harmful health effects of vibrations.

This paper presents the results of the fatigue tests carried out on different foam samples by pressing an indenter into the foams' surface that was much larger than the indenter's surface. A maximum value of the load used during the test was within a defined range in every fatigue cycle.

In order to test $150 \times 150 \times 50 \mathrm{~mm}$ foam samples a special indenter was designed and manufactured according to the PN-EN ISO 3385 and PN-EN ISO 2439 standards. The indenter's dimensions were consistent with the standards in relation to the tested foams' size.

The fatigue tests of both conventional and auxetic foams were carried out according to the above given standards by applying 80,000 load cycles at 70 cycle/min frequency. Tests of viscoelastic foam and multilayer foam specimens, for which the upper layer was made of viscoelastic foam, were carried out according to the ASTM D 3574 standard applying 12,000 load cycles at 10 cycle/min frequency. All the tests were carried out using the MTS 370.10 strength testing machine.

Changes in thickness and density were determined throughout the tests. Moreover, the influence of the volumetric compression ratio on the fatigue properties of auxetic foam samples and the dependence of foam deflection on the number of cycles were examined. Finally, the test results obtained for conventional and auxetic foams were compared and discussed.
\end{abstract}

Keywords: cellular plastics, fatigue properties investigations, helicopter pilot seats.

\section{INTRODUCTION}

Polyurethane foams are nowadays used in particular in the automotive industry and transportation (the so-called technical foams) e.g. in crew seats cushion inserts of helicopters operated by the Polish Armed Forces. Elastic auxetic foam is a new type of material exhibiting 
different properties compared to conventional polyurethane foams. Firstly, the Poisson's ratio of the auxetic foams is negative - under tension they expand in transverse directions (Fig. 1). Secondly, due to the negative Poisson's ratio (NPR), these materials tend to wrap around crumple zones, which is not observed for conventional materials [1].

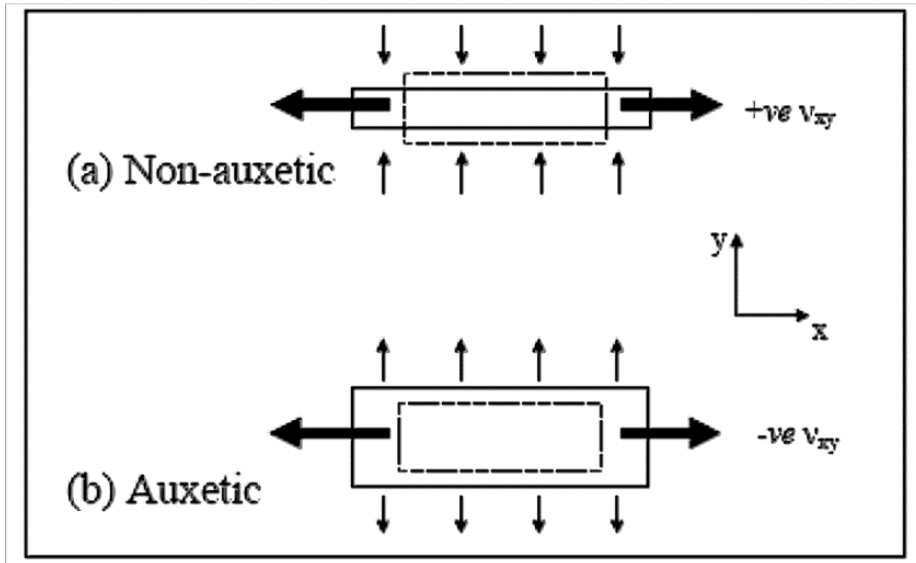

Fig. 1. Deformation under load for the initial (dashed line) and strained (continuous line) material: a) conventional, b) auxetic [2]

The fatigue tests presented in this paper were carried out for the following polyurethane polyester foams: S28280, S364MD, Lam353D, D30130, polyurethane auxetic foams: S28280A, S364MDA, Lam353DA, D30130A, viscoelastic polyurethane foam V5030 and two-layered structures. Values of the Poisson's ratio for the examined foam samples are presented in Table 1.

Table 1. Minimal values of the Poisson's ratio for samples under $30 \%$ strain

\begin{tabular}{|c|c|c|}
\hline Foam type & $\begin{array}{c}\text { Volumetric compression } \\
\text { ratio } \mathrm{R}_{\mathrm{CV}}\end{array}$ & Poisson's ratio $v$ \\
\hline S28280 & --- & 0.450 \\
\hline S364MD & --- & 0.370 \\
\hline Lam353D & --- & 0.290 \\
\hline D30130 & --- & 0.330 \\
\hline V5030 & --- & 0.390 \\
\hline S364MDA & 2.0 & -0.111 \\
\hline Lam353MDA & 2.0 & -0.088 \\
\hline D30130A & 2.0 & -0.120 \\
\hline S28280A & 2.2 & -0.110 \\
\hline S28280A & 3.1 & -0.130 \\
\hline S28280A & 4.4 & -0.040 \\
\hline
\end{tabular}

\section{PREPARATION AND CONDUCT OF THE TEST}

The auxetic foams were manufactured by a multistage compression method using a chemical solvent for softening the specimen. The final dimensions of the processed specimens were 
determined using the thermal method by exposing the specimen to temperature close (but below) the softening temperature of foams. A characteristic parameter of the manufactured foams is the volumetric compression ratio $R_{C V}=V_{p} / V_{a}$ (where $V_{p}$ - initial volume of the foam specimen before processing, $\mathrm{V}_{\mathrm{a}}$ - final volume of the processed foam) [1]. The final dimensions of processed auxetic foams were $150 \times 150 \times 50 \mathrm{~mm}$.

The fatigue test was carried out under constant load by pressing the indenter into a foam sample having the upper surface larger than the indenter's surface. The maximum value of the exerted load was within a defined range for every cycle.

The test was based on the PN-EN ISO 3385 [3] (determination of fatigue under constant load) and PN-EN ISO 2439 [4] (determination of hardness by the indentation technique) standards.

Since the carried out tests were comparable and the processed auxetics foam samples were block-shaped (rectangular parallelepiped with dimensions 150x150x50 mm), the indenter was designed preserving the dimensional proportions given for the normalized sample (380x380 mm) the used indenter head was $99 \mathrm{~mm}$ in diameter and the lower edge was rounded with $25 \mathrm{~mm}$ radius [5]. The same principle was used during design of the hardness measurement indenter based on the PN-EN ISO 2439 standard. Hence the prepared indenter was $79 \mathrm{~mm}$ in diameter and the lower edge was rounded with $1 \mathrm{~mm}$ radius.

The fatigue test of polyurethane foams under constant load involves the following steps: firstly, thickness and hardness measurements (method A - 40\% indentation) of the foam specimens are carried out prior to the test, secondly 80,000 load cycles are exerted on the specimen, after which the sample is resting for $10 \mathrm{~min}$, and, finally, thickness and hardness tests are carried out once more [3].

For the prepared indenter 80,000 cycles were used with $117 \mathrm{~N} \pm 3 \mathrm{~N}$ load, proportional to the normalized load. The loading frequency was $70 \mathrm{cycles} / \mathrm{min}$. During the fatigue test of viscoelastic and 2-layered foam samples with viscoelastic upper layer, test parameters defined in the ASTM D 3574 [7] standard were used: 12,000 cycles under the above defined load at 10 cycle/min loading frequency. Figure 2 shows the indenter and the auxetic foam sample before and during the fatigue test [6]. The test was carried out using the MTS 370.10 strength testing machine.

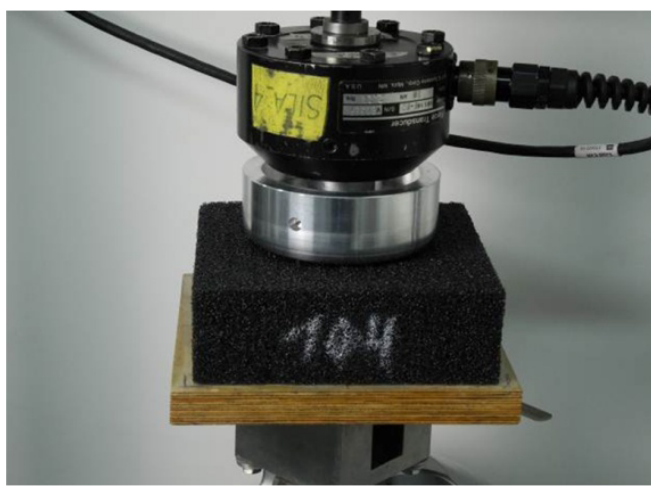

a)

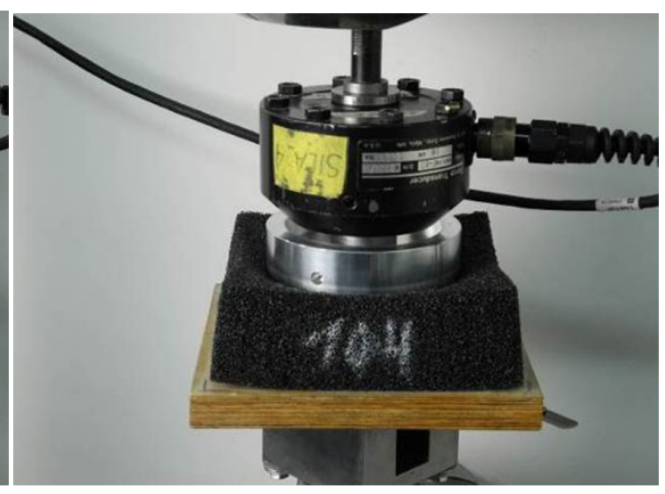

b)

Fig. 2. Indenter and $\mathbf{S 2 8 2 8 0}$ auxetic foam sample: a) before the test, $b$ ) during 40,000 cycle [6]

\section{TEST RESULTS}

The fatigue test results are presented as thickness change $\Delta d=d_{1}-d_{2}$ (where $d_{1}-$ initial thickness and $\mathrm{d}_{2}$ - final thickness), hardness change $\Delta \mathrm{H}=\mathrm{H}_{1}-\mathrm{H}_{2}$ (where $\mathrm{H}_{1}-$ initial hardness and $\mathrm{H}_{2}$ - final hardness) and foam sample deformation after the test.

The selected test method allows assessing the utility properties of elastic porous latex and polyurethane polyether materials used as seat cushion inserts. Nevertheless, it was adopted for 
polyurethane polyester auxetic foams as well as viscoelastic foam due to potentially similar applications. Changes in thickness and hardness of the foams determined during the test can correspond to changes which will occur during usage.

The fatigue test results presented as defined thickness and hardness change of the chosen types of polyurethane foams and specimens processed to auxetic foams for the volumetric compression ratio $R_{C V} \sim 2$ are shown in Figure 3.

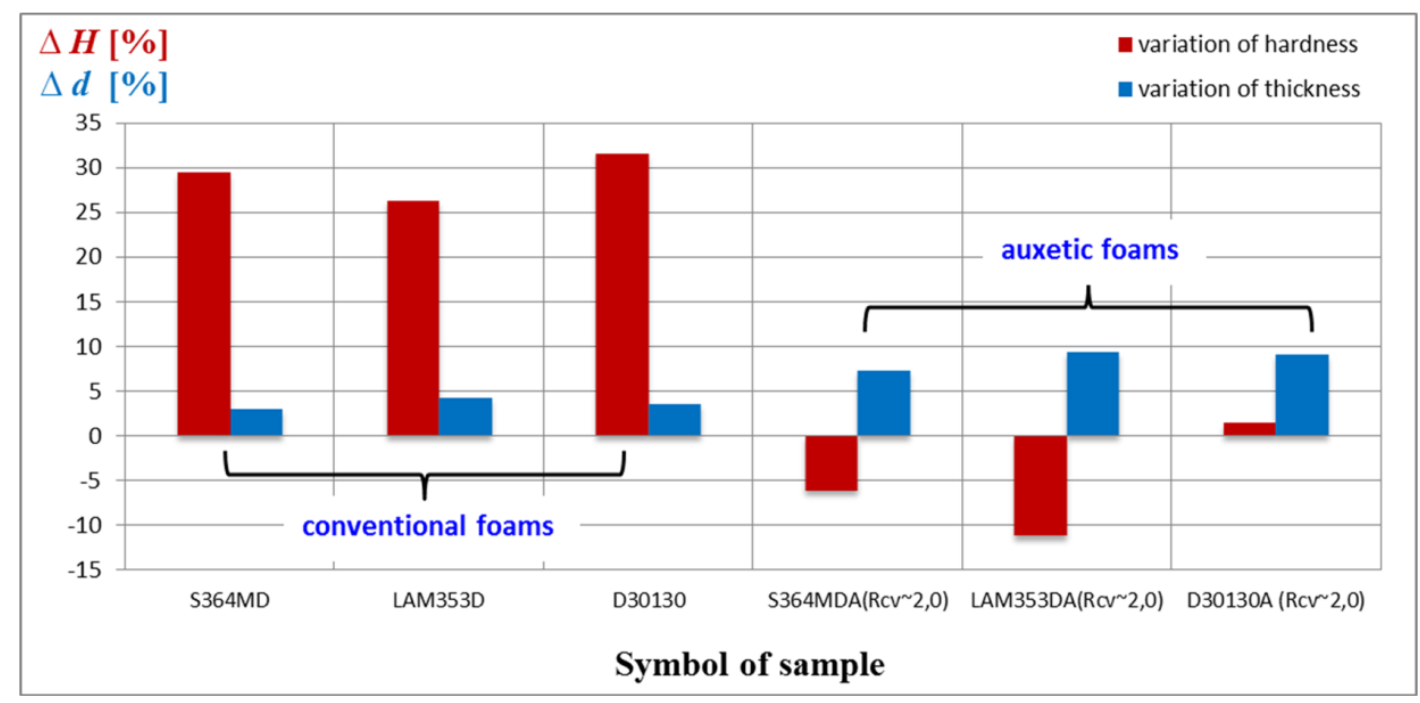

Fig. 3. Determined values of thickness and hardness change for the selected types of polyurethane foams and processed auxetic foams (volumetric compression ratio $R_{C V} \sim 2$ )

The presented results indicate that the tested auxetic foams, unlike the tested conventional foams, show the tendency to increase their stiffness (stiffen up) due to applied load.

Auxetic materials do not deform as easily as conventional ones and exhibit much greater resistance to penetration. Whenever a conventional material is exposed to impact load it compensates the impact force by deforming outwards to the impact region. On the contrary, auxetic materials deform towards the impact region, which causes the local cellular structure to densify and increase resistance of the material to penetration [8].

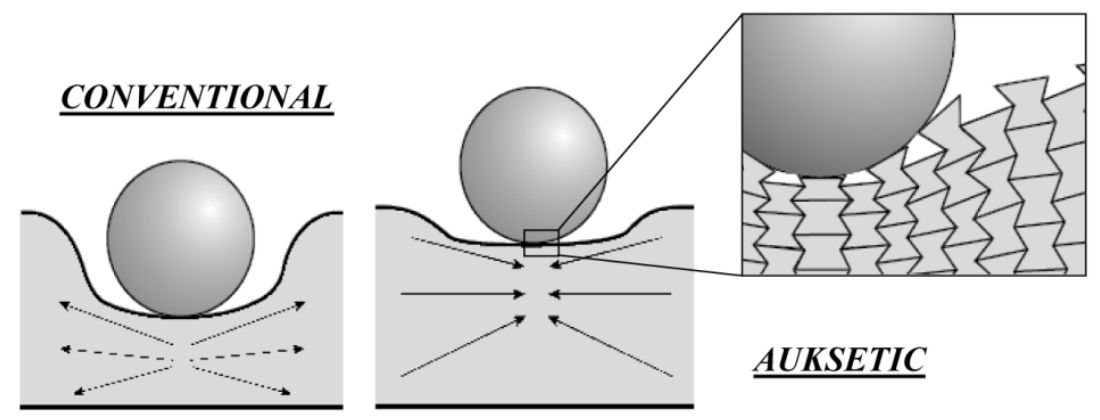

Fig. 4. Behavior of conventional and auxetic materials under impact load impact [8]

Moreover, auxetic specimens show greater, though not exceeding 10\%, thickness changes after the fatigue test in comparison to conventional foam specimens.

The fatigue test results presented as determined thickness and hardness changes for auxetic $\mathrm{S} 28280$ A foam samples processed with $\mathrm{R}_{\mathrm{CV}} \sim 2.2 \div 4.5$ are shown in Figure 5 .

The presented results indicate that the value of the volumetric compression ratio influences the change in thickness as well as hardness of the tested sample. The greatest hardness change (stiffening up) was observed for $\mathrm{R}_{\mathrm{CV}} \sim 3$. 


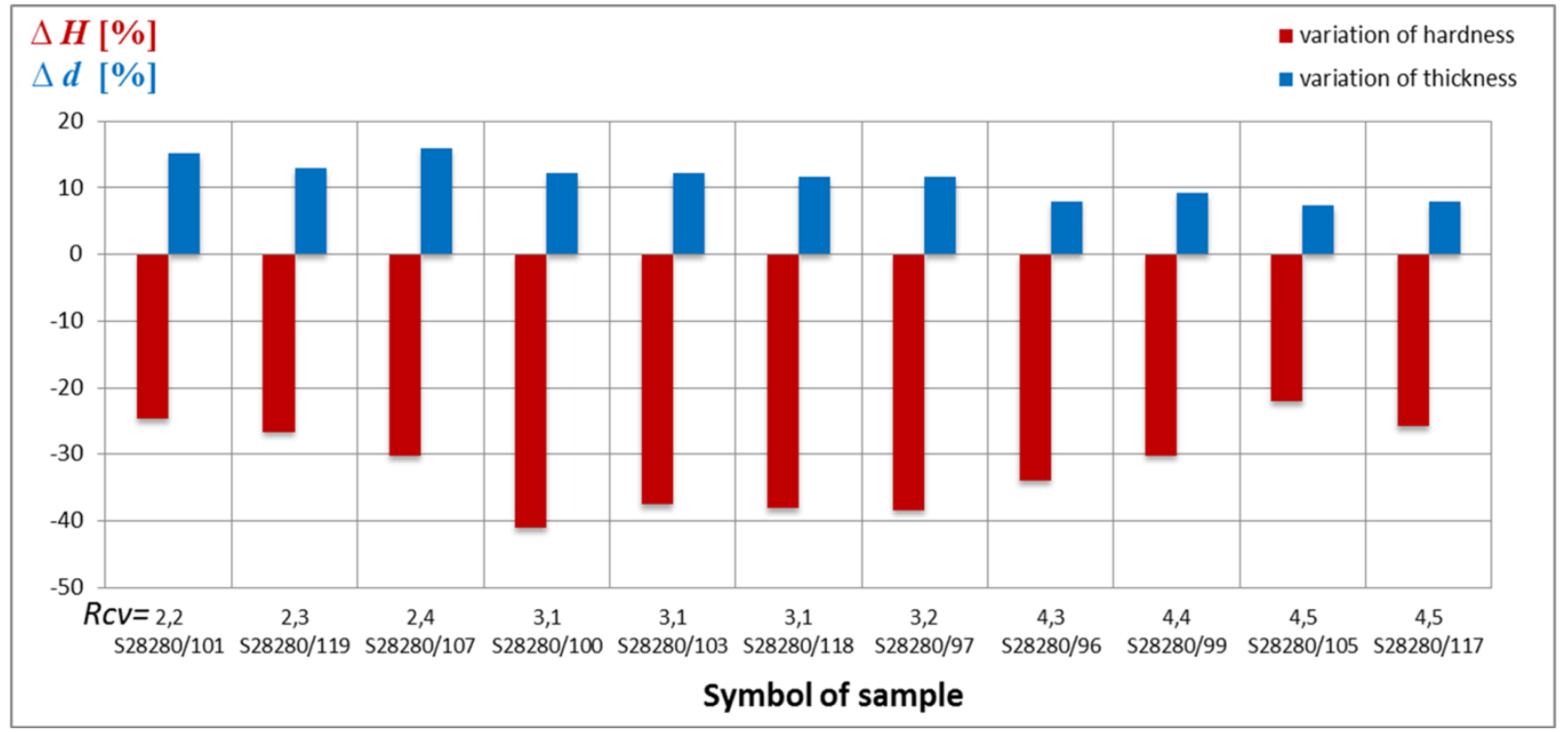

Fig. 5. Determined values of thickness and hardness changes for the auxetic $\mathbf{2 8 2 8 0}$ foam samples - influence of the volumetric compression ratio

The fatigue test was carried out also for the 2-layered structures composed of conventional viscoelastic foam and processed $\left(\mathrm{R}_{\mathrm{CV}} \sim 2.0\right)$ auxetic S364MDA foam bonded together with Bonidur CNT-267 adhesive.

The fatigue test results i.e. thickness and hardness change, for auxetic foam samples, viscoelastic foam samples and bonded 2-layered structures composed of both types of foams are shown in Figure 6.

The presented results indicate that hardness of S364MDA auxetic foam samples is greater after the fatigue test than prior to it. For V5030 viscoelastic foam and 2-layered structures, the opposite is true. These samples show smaller hardness after the fatigue test than prior to it. The scope of hardness change for 2-layered structures is greater than for the viscoelastic foam itself. The change in thickness for 2- layered structures is between changes reached by the two layers tested separately.

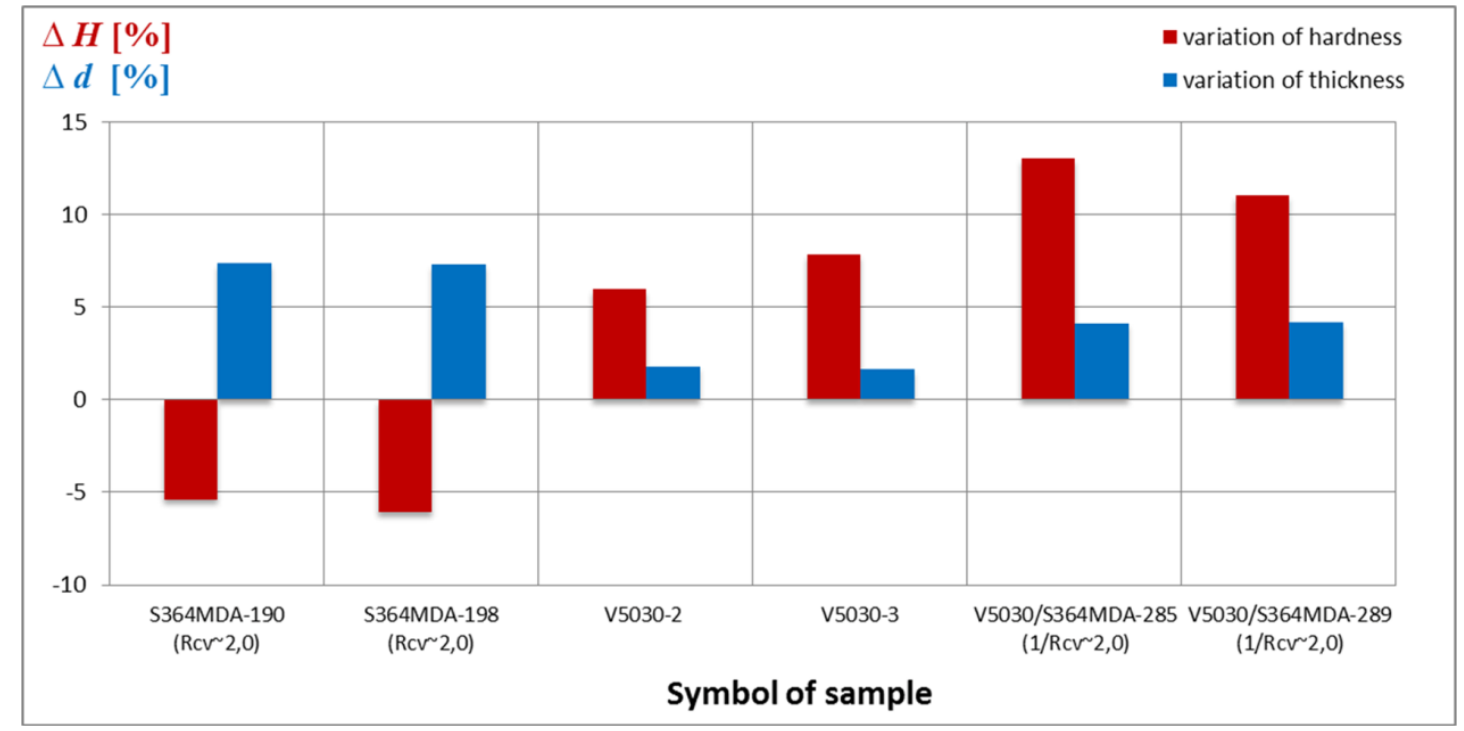

Fig. 6. Determined values of thickness and hardness change for S364MDA auxetic samples $\left(R_{C V} \sim 2.0\right)$, V5030 viscoelastic foam samples and 2-layered structures composed of S364MDA and V5030 foams 
Figure 7. shows dependence of the deflection change (in respect to the initial thickness) versus number of cycles (normalized value) for the conventional S364MD foam and processed from it auxetic S364MDA foam. Change of deflection, for each load cycle, was defined as the difference between deflection under maximum and minimum load.

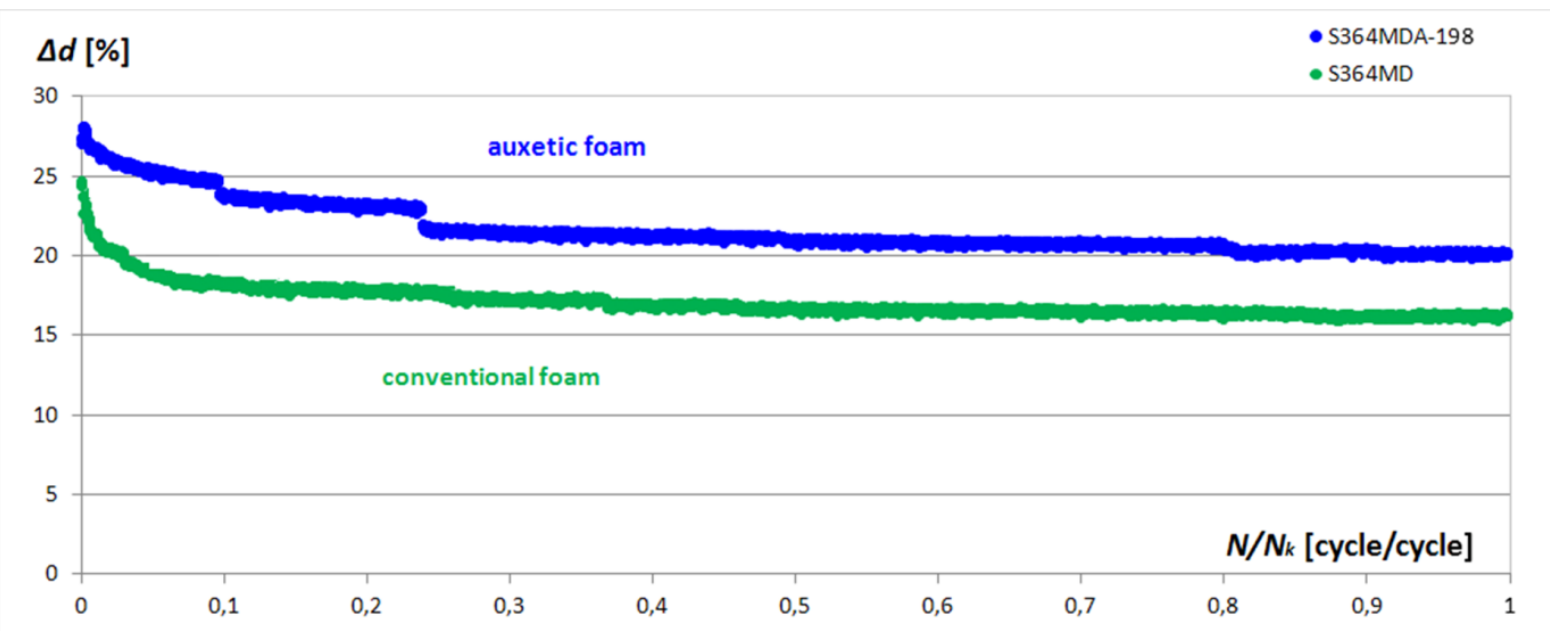

Fig. 7. Deflection change in comparison to initial thickness for the conventional S364MD and processed auxetic S364MDA foam

Based on this dependence it can be concluded that the auxetic sample exhibits larger deflection comparied to the conventional foam from which it was manufactured. Deflection change for the auxetic S364MDA foam, V5030 viscoelastic foam and 2-layered structure composed of latter foams is shown in Fig. 8.

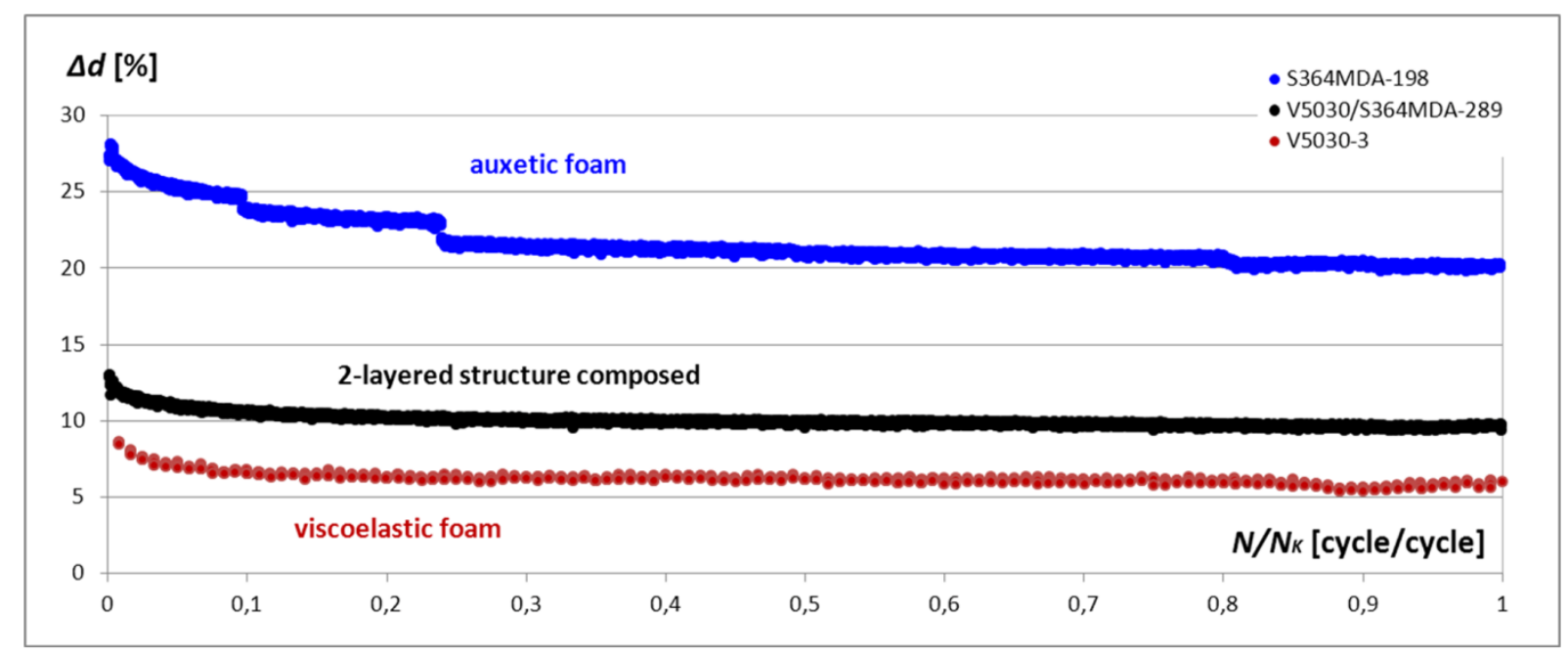

Fig. 8. Deflection change in comparison to the initial thickness for the auxetic S364MDA foam, viscoelastic V5030 foam and the 2-layered structure composed of the latter foams

Based on the presented characteristic it can be deduced that the viscoelastic foams show the smallest deflection changes compared to the auxetic S364MDA foam samples and the 2-layered foam structures. Values of deflection for the 2-layered structure are in between the values reached by the components but closer to those of the viscoelastic foam, hence viscoelastic foam has a more significant impact on the overall behavior of the 2-layerd structure during the fatigue test. 


\section{SUMMARY}

The presented fatigue test results show that:

- conventional foam samples after processing to auxetic foams show the negative Poisson's ratio,

- S364MD, D30130 and LAM353D conventional foam samples after the fatigue test show about $30 \%$ hardness loss,

- S364MDA, S28280A and LAM353DA auxetic foam samples after the fatigue test show an increase in measured hardness 5\%, 40\% (for $\mathrm{R}_{\mathrm{CV}}$ 3) and 10\%, respectively. D30130A auxetic foam samples show a slight loss in hardness,

- S28280A auxetic foam samples show the greatest increase in hardness due to fatigue load for the volumetric compression ratio $\mathrm{R}_{\mathrm{CV}} \sim 3$ in the $\sim 2<\mathrm{R}_{\mathrm{CV}}<\sim 4.5$ range,

- S364MDA auxetic foam samples show higher deflection change due to fatigue load than the S364MDA conventional foam from which they were manufactured,

- the viscoelastic foam has a significant influence on the behavior of the 2-layered structure during the fatigue test.

\section{ACKNOWLEDGEMENTS}

Financial support of the Structural Funds in the Operational Programme - Innovative Economy (IE OP) financed from the European Regional Development Fund - Project "Modern material technologies in aerospace industry", No. POIG.01.01.02-00-015/08-00 is gratefully acknowledged.

\section{REFERENCES}

1. R. S. Lakes, Science, v. 235 (1987) $1038 \div 1040$.

2. A. Anderson, home.um.edu.mt/ncs/ncs3/alderson.pdf.

3. PN-EN ISO 3385-99, Elastyczne tworzywa porowate; oznaczanie zmęczenia przy statym obciażeniu.

4. PN-EN ISO 2439-10 Elastyczne tworzywa sztuczne porowate; oznaczanie twardości (technika wciskania).

5. Lisiecki J. i zespół: Sprawozdanie ITWL Nr SP-105/31/2012 z pracy „Badanie elastycznej pianki poliuretanowej o ujemnym współczynniku Poissona. Określenie wpływu parametrów termicznych procesu wytwarzania pianek na właściwości wytrzymałościowe kształtek 150x150x50 mm o różnym stopniu zagęszczenia”, POIG, ZB14, September 2012.

6. Lisiecki J. i zespół: Sprawozdanie ITWL Nr SP-147/31/2012 z pracy „Badanie elastycznej pianki poliuretanowej o ujemnym współczynniku Poissona. Badanie wpływu sposobu zagęszczenia kształtek pianki auksetycznej na współczynnik Poissona i właściwości użytkowe - cz. I.", POIG, ZB14, grudzień 2012.

7. ASTM D 3574-11, Standard test method for flexible cellular materials-slab, bonded, and molded urethane foams.

8. J.N. Grima, A. Attard, R. Gatt, N.R. Cassar, Advanced Engineering Materials, v.21, 2009. 